\title{
0 princípio da precaução como uma ferramenta estratégica para redesenhar a (sub)política. Compreensão e perspectivas da ciência política de língua francesa ${ }^{1}$
}

\section{Resumo}

O princípio da precaução está inserido em um contexto decisional em evolução, marcado por uma incerteza multidimensional com relação às conseqüências ambientais, econômicas, sociais, éticas e políticas das inovações tecnológicas. $\mathrm{Na}$ ciência política de língua francesa, o princípio funciona como uma ferramenta estratégica, uma resposta política ao surgimento de um novo fluxo de incerteza social, voltada principalmente para as inseguranças do mundo científico. Neste trabalho, afirmamos que o princípio da precaução redefine a forma de gerir a incerteza científica, em uma sociedade caracterizada pela indefinição das fronteiras entre atores políticos e subpolíticos. Em sua aplicação, há uma linha de ruptura que reduz a margem de manobra decisória de determinadas entidades subpolíticas, enquanto incentiva outras a agirem. Contudo, enfatizamos que, em um mundo cada vez mais globalizado e interligado, os efeitos da aplicação do princípio da precaução são temporários e locais. Ainda assim, o princípio pode contribuir para os importantes debates a serem desenvolvidos em espaços institucionais, para uma ação reflexiva antecipatória e de apoio à decisão ${ }^{2}$.

Palavras-chave: Princípio da precaução. Incerteza.

1 Tradução de Marcelo Otto Severo.

* Professor de Ciência Política na Universidade de Liège, Bélgica; e Diretor da SPIRAL (Scientific and Public Involvement in Risk Allocations Laboratory). sebastien.brunet@ulg.ac.be

** Pesquisador pós-doutorado da Universidade de Liège; responsável pela unidade de pesquisas em Estudos de Ciência e Tecnologia na SPIRAL.

*** Joris Geoffrey é aspirante ao FNRS, na Universidade de Liège (SPIRAL). Doutorando, responsável pela avaliação dos polos de competitividade em Valônia (Serviço Público de Valônia). joris.geoffrey@ulg.ac.be

2 Uma versão anterior deste artigo foi publicada (em francês) na Revue Suisse de Sociologie (2007), vol.33. Título original: "Le principe de précaution: un outil stratégique de transformation (sub)politique". 


\section{Contextualização do princípio da precaução}

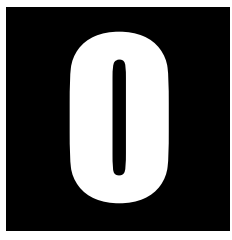

princípio da precaução está ancorado nas teorias da Escola de Frankfurt. Sua definição legal data da década de oitenta (Hey, 1991:244; Stebbing, 1992:287), mas ele só foi oficialmente reconhecido na Conferência das Nações Unidas sobre o Meio Ambiente e o Desenvolvimento, realizada no Rio de Janeiro em 1992 (Kourilsky e Viney, 2000:11). O princípio da precaução foi apresentado como uma recomendação oficial aos governos, para que a ausência de garantias científicas não pudesse justificar atrasos na adoção de medidas preventivas elaboradas para evitar riscos que poderiam provocar danos graves e/ou irreversíveis ao meio ambiente (Cousy, 1995:151).

O princípio da precaução foi reconhecido primeiro no âmbito da política ambiental, mas se tem expandido para outros domínios, como os direitos do consumidor, a proteção à saúde (Dubuisson em Hupet (org.), 2001:119), e as liberdades públicas (Kourilsky e Viney, 2000:39). Seu uso recorrente, em contextos e objetivos heterogêneos, fez com que o princípio da precaução fosse elevado ao nível discursivo.Parece cada vez mais óbvio que este princípio, originalmente limitado, está se tornando um quadro de referência global para atores públicos e privados.

Na França, a natureza e o escopo do princípio da precaução foram analisados sob uma perspectiva histórica pelo filósofo François Ewald. Segundo Ewald, o princípio da precaução é o resultado de três regimes de organização de responsabilidade social que se sucedem desde 1804. O primeiro regime, chamado de Estado-providência, é articulado em torno do conceito de responsabilidade e culpabilidade individual que dominou o século XIX. O segundo é chamado de regime de solidariedade, com base no conceito de risco e solidariedade social que se desenvolveu 
durante o século XX. O terceiro é estruturado em torno do conceito de segurança, no qual o princípio da precaução revela-se um modo de gestão da incerteza (Ewald, 1996a; Giddens, 1990). Mesmo que não esteja explícito na obra de Ewald, os três períodos paradigmáticos (providência, solidariedade e segurança), apesar de se terem desenvolvido em diferentes momentos da História, não se anulam, mas se sobrepõem. Na verdade, acreditamos que um paradigma não rejeita os anteriores, mas que os três coexistem e um predomina, conforme o regime de regulação de risco vigente. No entanto, para efeitos de clareza analítica, vamos manter uma distinção entre os três regimes, onde cada dispositivo corresponde a um determinado período paradigmático.

O regime da providência estabelece o paradigma da responsabilidade individual e a virtude como pontos focais. As estruturas sociais são articuladas em torno de direitos e deveres estruturados através de um forte sistema moral de referência. Neste paradigma, sob o signo do individualismo, qualquer ator social pode usar sua liberdade pessoal para agir com prudência. Os indivíduos assumem os perigos e os riscos do cotidiano sem qualquer apoio, público ou econômico, oferecido ou legitimado. Dessa forma, a exposição aos riscos profissionais está a cargo dos indivíduos e de uma estratégia prudente, com o devido cuidado. Os trabalhos preparatórios do Código Civil não deixam a menor dúvida quanto à imputação de responsabilidade. Seus elaboradores imaginaram que o conceito de "culpa" seria a melhor ferramenta para regular o senso de responsabilidade dos indivíduos (Ewald, 1996b:56). Este período paradigmático está intrinsecamente relacionado com o liberalismo do século XIX. Se "eu" não entendo as leis naturais e aquelas fundadas pela sociedade em que "eu" vivo, a culpa é "minha", e "eu" devo assumir as conseqüências. É, portanto, uma espécie de auto-regulação do comportamento que aproxima o erro e a culpa. As injustiças sociais que resultam da aplicação 
sistemática do regime da providência, principalmente no âmbito dos acidentes de trabalho, tornam inevitáveis as mudanças sociais e políticas.

A solidariedade é o lema do segundo período paradigmático que, historicamente, coincide com o advento do estado de bem-estar social. No paradigma da solidariedade, as autoridades fazem uso de seu poder regulamentador para induzir a multiplicação dos direitos sociais e o reconhecimento de um direito a uma indenização contra os perigos da vida. Esses novos direitos permitem uma profunda modificação da nossa ligação com os riscos. É como uma utopia científica e técnica, na qual se considera que a ciência desfruta de um controle total sobre si mesma, em conformidade com a ficção modernista onde a ciência e a tecnologia avançam e consolidam os progressos sociais. Como os perigos tornaramse riscos, este paradigma está vinculado à demanda por prevenção (contra doenças, crimes, acidentes, miséria, insegurança). O conceito de risco é, contudo, suficiente para descrever as situações de insegurança. Além disso, uma vez que os riscos são previsíveis, por sua probabilidade de ocorrência, os meios de prevenção podem ser estabelecidos a partir do que sabemos a priori (probabilidade e sistema de seguros). A capacidade de determinar com precisão os custos sociais e econômicos para a sociedade, através de seus representantes, é responsável pelos riscos e estabelece medidas concebidas para garantir a solidariedade. Um sistema de compensação dos riscos é estabelecido. Este é justificado pela existência de riscos inevitáveis ou residuais, independentes da atitude virtuosa ou prudente dos atores sociais (uma distribuição social do dano incompreensível). Ao contrário do que dizem os autores do código civil, a despeito dos cuidados dos indivíduos, o risco é uma variável endógena em nossa sociedade. Conseqüentemente, o conceito de "responsabilidade", desvinculado da prudência, assume a forma de uma abordagem preventiva, proporcionada pelo conhecimento científico. 
O terceiro período, que estabelece o conceito de "segurança", começou com as questões ambientais (contestadas) das décadas de 1970 e 1980. Este período é marcado pelo despertar das sociedades desenvolvidas para a vulnerabilidade, diante dos novos riscos, caracterizados por incertezas múltiplas. Ao assumirem esses riscos, os atores sociais encontram os limites de um sistema baseado em probabilidades e redescobrem a presença de calamidades, cuja origem e conseqüências não podem mais ser atribuídas a Deus ou à Providência, mas à responsabilidade humana. Ao contrário do paradigma anterior (segurança), as vítimas têm uma nova relação com o dano, caracterizado pela sua gravidade e natureza irreversível. Neste contexto, o status da ciência é questionado e o sistema de compensação financeira está longe de ser adequado ou socialmente aceitável. Os novos riscos, que serão chamados de "riscos modernos", nos levam a repensar as instituições industrializadas, que deveriam ser responsáveis pela gestão dos riscos.

\section{Risco moderno: uma ferramenta para compreender melhor o paradigma da segurança}

Apesar da grande influência que teve a perspectiva de Ewald sobre a forma como foi entendido o princípio da precaução na França, sua análise só pode ser plenamente compreendida ao colocá-la em perspectiva com o conceito de "risco moderno", desenvolvido pelo sociólogo Ulrich Beck. Em seu livro "Risikogesellschaft" (1986)*, Beck destaca a passagem de uma sociedade industrial para uma sociedade de risco, e o advento da incerteza que vem com ela. De fato, segundo Beck, somos testemunhas da transformação do paradigma positivista da sociedade industrial, resul-

\footnotetext{
* Publicado no Brasil como "A Sociedade do Risco: rumo a uma nova modernidade" (2010).
} 
tado do surgimento de "novos riscos civilizacionais", também chamados de riscos "modernos".

Esses novos riscos têm uma dimensão global (tanto em termos espaciais quanto temporais ou multidimensionais), são invisíveis (só podem ser acessados por cientistas especializados), irreversíveis (transformam a natureza da Natureza) e irrevogáveis (o paradigma do seguro torna-se insuficiente para reparar o dano causado). Estes novos riscos, qualificados como "modernos", são uma conseqüência da atividade tecnológica. Beck menciona "efeitos colaterais" para referir-se aos efeitos secundários, invisíveis, que vêm com a inovação tecnológica, aos quais é necessário adaptar-se. O desenvolvimento tecnológico, principalmente aquele proporcionado pelo modelo científico ocidental, está na origem do desenvolvimento desses novos riscos. A atividade científica não só está na fonte dos novos riscos, como também é chamada para identificar e resolver esses mesmos riscos. As pessoas expostas aos riscos modernos não possuem os conhecimentos técnicos e científicos necessários para identificar e avaliar esses riscos. A maior parte da população continua dependente dos cientistas para compreender os riscos e o potencial de dano. Além disso, com a disseminação desses novos riscos, os cientistas estão diante de novos problemas, para os quais eles não têm o conhecimento adequado. Conseqüentemente, testemunhamos uma dupla perda de soberania: para os indivíduos, de um lado, e para os cientistas, de outro.

Os riscos inscrevem-se em uma construção científica e política, em três sentidos diferentes: a ciência torna-se uma causa (parcial), um meio de definição, e uma fonte de resolução de riscos (Beck, 2001). O risco torna-se uma medida fundamental de organização, com relação à vida dos indivíduos e ao futuro do nosso planeta (Giddens em Audet e Bouchkhi, 1993). Segundo Beck, as sociedades de risco não são exatamente sociedades de classe. O risco tem um efeito de nivelamento que impede 
o raciocínio em termos de classe exposta e classe não-exposta. Ocorre um "efeito bumerangue", reforçado pela globalização dos riscos que, mais cedo ou mais tarde, acaba por ameaçar aqueles que os produzem ou se beneficiam deles.

No entanto, parece abusivo afirmar que o período paradigmático da segurança elimina completamente as desigualdades sociais. Quando se trata de riscos modernos, existem processos de alocação de riscos, que seguem os modelos anteriores de distribuição de riqueza. A ruptura social reaparece. Soa como uma utopia pensar que todos estão em pé de igualdade por causa dos riscos modernos, uma vez que o conhecimento é um elemento essencial na construção de uma estratégia de prevenção ou de precaução. E, como o conhecimento é mobilizado pelas classes sociais favorecidas, estas estão mais bem preparadas para os novos riscos que podem surgir. Logo, a igualdade sugerida por Beck é muito relativa. Sendo assim, se por um lado os riscos modernos participam do processo de destruição da sociedade de classes, por outro lado, lançam as bases de uma nova forma de desigualdade.

Conseqüentemente, há um repentino surgimento de novas desigualdades sociais na exposição ao risco. Muitas vezes, situações de pobreza extrema trazem consigo situações de extremo risco. Paradoxalmente, os exemplos de despertar e de comprometimento mais importantes são observados nos países desenvolvidos, onde a ameaça é menor. Parece, então, que os países em desenvolvimento estão mais preocupados com a gestão dos riscos industriais do que com os riscos modernos.A sociedade de risco cria uma ruptura social através de ameaças invisíveis e adota o modelo das sociedades de classes, responsável por uma ruptura social visível. Em outras palavras, nas sociedades industrializadas, a redistribuição da riqueza é caracterizada por alguma visibilidade social e uma produção de riscos menos visível. Esta invisibilidade social provoca preocupação 
social quando as incertezas permeiam a avaliação e a gestão desses riscos e levam ao esgotamento das interpretações sobre os mesmos. Os riscos modernos, então, se apresentam como uma nova afirmação social, no que diz respeito à gestão da incerteza científica que eles mesmos geram.

Nestas condições, as políticas precisam modernizar os padrões de gestão de risco, de acordo com os novos desafios de um período de turbulência e instabilidade. São necessários, portanto, novos instrumentos para adaptar suas próprias estratégias, para conviver com a ambigüidade e para lidar com soluções múltiplas e condicionais. Enquanto assistimos a uma redefinição das prioridades políticas em direção a uma agenda de desenvolvimento sustentável, o princípio da precaução surge como uma ferramenta política para tentar lidar com as tensões entre a natureza e a sociedade (industrializada).

\section{Uma política para tentar orientar a "tecnonatureza"}

A precaução parece criar uma abordagem específica da relação "sociedade-Natureza". Enquanto o conceito de "sociedade industrial" repousava sobre a oposição entre natureza e sociedade, a "sociedade de risco" toma como ponto de partida a idéia de que a natureza está integrada na civilização. Conseqüentemente, o caráter indivisível da "Natureza" e da "Técnica", favorece o surgimento de uma "tecnonatureza", que caracteriza o nosso ambiente "natural". Este parece ser, quase que completamente, produto da atividade técnica. Torna-se difícil compreender a distinção entre Natureza e Sociedade (ou Técnica), quando a nossa "Natureza" se transforma em um gigantesco objeto técnico (Roqueplo, 1993:18). Essa "tecnonatureza" não é, de forma alguma, uma antinatureza, só porque foi produzida pela atividade técnica da sociedade industrial. A Técnica encontrou na Natureza as condições necessárias para a sua instrumen- 
talização. Na mesma linha, a "tecnonatureza" é apenas a cristalização do desenvolvimento tecnológico que assume um duplo papel: por um lado, representa o conjunto das escolhas técnicas concretas socialmente realizadas, e, pelo outro, condiciona a atividade técnica que ainda está por vir (Roqueplo, 1993:121-122).

Se a "tecnonatureza" permanece, não é só porque a Natureza proporciona à atividade técnica o ambiente favorável ao seu desenvolvimento, mas é também porque, em um contexto positivista, a sociedade mantém as condições humanas e naturais do seu funcionamento. No entanto, o conceito de "tecnonatureza" não cobre a nova dinâmica política, social e científica, motivada pelo surgimento de novos riscos. De fato, a partir do momento em que se dá a passagem de uma separação visível entre Natureza e sociedade para um ambiente "tecnonatural", uma evolução da "tecnonatureza" parece emergir dos riscos modernos e do uso do princípio da precaução: uma "tecnonatureza politizada".

O princípio da precaução cria uma nova demanda por aceitação social, através da organização de um diálogo entre todos os atores envolvidos (mundo político e científico, parceiros socioeconômicos, sociedade civil). Esse diálogo se refere, em particular, à aplicação do princípio da precaução, não como um quadro referencial de ação, definindo o conteúdo da decisão, mas como um conjunto de regras processuais, estruturando o processo de tomada de decisão para que este possa ser descrito como "cauteloso" por todas as partes envolvidas. Em outras palavras, a necessidade de politizar a tecnonatureza reflete as tensões que existem entre as ideologias modernistas da tecnologia e do progresso, em um momento de maior preocupação com o desenvolvimento sustentável.

O ponto de partida de uma tecnonatureza politizada é o surgimento de novas abordagens - não só o uso do princípio da precaução, mas também o desenvolvimento de políticas deliberativas ou de Avaliação 
Tecnológica Participativa e Construtiva (Joss e Bellucci, 2002; Rip e Schot, 1997) - para lidar com as novas incertezas sociais. É esse tipo de resposta política que dá forma ao novo dinamismo da relação entre Natureza e Sociedade. A politização da tecnonatureza está relacionada a vários fatores, como, por exemplo, as inevitáveis conseqüências políticas da atividade dos cientistas, através dos efeitos do desenvolvimento tecnológico que eles tornaram possível. O surgimento repentino dos riscos modernos pode exortar a sociedade a redefinir os limites da tecnonatureza, mesmo que seja para acompanhar as novas formas (limitadas) de regulação ou controle por parte da esfera político-social. Uma "tecnonatureza politizada" seria, então, uma tecnonatureza selvagem e socialmente aceita. Para colocar de outra forma, uma "tecnonatureza politizada" poderia ser descrita como um gigantesco objeto técnico reprimido e sob o controle das formas de poder político que se desenvolveram no seio das sociedades pluralistas, uma vez que não há condições sociais para uma aceitação unânime do desenvolvimento tecnológico em um contexto ambíguo. No âmbito das políticas, as referências implícitas e explícitas à "modernização ecológica" (Mol, 1995; Mol e Spaaragen, 2000; York e Rosa, 2003) incorporam exemplos concretos de tentativas políticas de orientar a tecnonatureza conforme a dinâmica de uma agenda de desenvolvimento sustentável. Afirmamos, então, que a passagem para uma tecnonatureza politizada está em andamento, e que só vai se concretizar quando ferramentas como o princípio da precaução estiverem sistematicamente mobilizadas no processo de decisão pública, lidando com as incertezas do desenvolvimento técnico e científico.

Se a tecnonatureza politizada é uma resposta política às novas expectativas da sociedade, o princípio da precaução é uma forma de expressar essa necessidade social de politização. É uma prática política, uma nova ferramenta estratégica à disposição dos decisores públicos, beneficiados pela possibilidade legítima de decidir entre não agir ou agir de maneira 
diferente, considerando os riscos incorridos, em caso de extrema incerteza - especialmente nas áreas da saúde, alimentação e meio ambiente.

No entanto, ainda que o surgimento dos riscos modernos e o desenvolvimento de novas correntes epistemológicas tenham enfraquecido o discurso positivista, o princípio da precaução não é nada menos do que um apelo à especialização. Nestas condições, o paradigma positivista, mesmo que adaptado às novas realidades da tecnonatureza politizada, na qual a política exige da indústria uma produção voltada para a ecologia, ainda pode durar muito tempo. Ele vai dissolver-se aos poucos, se o discurso científico conseguir manter intacta a sua glória para apoiar o processo decisório na maioria dos riscos. Mas, no que diz respeito à legitimidade política e à aceitação social, os novos riscos surgem para questionar as bases modernas da ação pública. O paradigma possibilita a abertura do processo decisório, a fim de construir legitimidade pública e eficiência.

\section{Gestão da incerteza científica em uma "tecnonatureza politizada"}

É impressionante observar como algumas partes - cidadãos, decisores políticos, sociedade civil, cientistas, atores socioeconômicos - enfrentam a incerteza de maneira completamente diferente. Se alguém adota uma abordagem falsificacionista da ciência, logo percebe os laços que o modelo do conhecimento científico mantém com o conceito de incerteza. Se olharmos mais de perto o trabalho de Karl Popper (Popper, 1963), podemos ver que a ciência começa com a sugestão de conjecturas ou suposições. A comunidade científica, então, tem a oportunidade de refutá-las ao confrontá-las com experimentos, razão pela qual, nenhuma teoria científica ou lei geral é definitiva (Chalmers, 1987). 
Segundo a concepção epistemológica de Popper, o trabalho científico é um trabalho de imaginação, de invenção, através do qual a comunidade científica substitui algumas representações do mundo por outras, consideradas mais adequadas conforme os projetos escolhidos pelos seres humanos. Cada disciplina é, portanto, uma construção histórica, condicionada por um determinado período de tempo e projetos (Fourez, 1986).

O modelo teórico de representação, desenvolvido em um determinado contexto e momento, seria, portanto, o produto de uma intersubjetividade construtiva. A abordagem falsificacionista favorece o progresso científico no equilíbrio entre certeza e incerteza. A onipresença da incerteza leva o cientista a concordar com a produção de um nível limitado de certeza pendente. Até porque, se, mais tarde, a certeza das teorias (ainda?) não-falsificadas admitir o progresso, a possibilidade de um ressurgimento da incerteza no raciocínio científico vai levar ao aprimoramento do discurso que deve legitimar o desenvolvimento técnico.

Além disso, se a alternância entre certeza e incerteza tem caracterizado a abordagem científica, a percepção que os atores sociais têm da incerteza em torno da produção científica esteve limitada, ou inexistente, por um longo período de tempo - certamente porque o cientista, apesar da incerteza à sua volta, quase sempre obtinha apoio para as partes consolidadas de sua disciplina, a fim de criar uma sensação de certeza fora de sua esfera. Dessa forma, a sociedade era tratada como um simples espectador, sem nenhuma influência sobre a abordagem científica e seu sistema operacional. Como já foi dito, uma das conseqüências da sociedade industrial é a produção de uma tecnonatureza sem controle político, ao passo que a invisibilidade social dos riscos consolida o positivismo ambiente. Mas esta ideologia positivista só é possível porque os sinais que emanam da esfera científica são sinais de certeza, que dão legitimidade à posição da ciência como desencantadora, capaz de prever a "certeza". 
Sem desmerecer a "inversão da razão" (Baudouin, 2002), adotada pelos representantes da Escola de Frankfurt, podemos dizer que, do ponto de vista social, essa confiança no progresso científico ofusca qualquer reavaliação da natureza humana da construção científica e só permite uma visão reconfortante da ciência, à qual cabe a delicada missão de gerir a incerteza pendente. A ruptura que marca o início do questionamento epistemológico da ciência começa com as obras de Thomas Kuhn (Kuhn, 1983 [1962]), que surge como um precursor e substitui a influência do contexto social no centro da produção da dinâmica do conhecimento.

Posteriormente, a evolução da complexidade tecnológica, em conjunto com as mudanças estruturais e culturais da sociedade moderna, trará um novo tipo de incerteza político-social e redefinirá os métodos de ação da sociedade para a abordagem científica. O surgimento dos riscos modernos e de questões internas no mundo científico, quanto à sua interpretação, faz com que os cientistas (até então desencantadores legítimos) ofereçam à esfera social sinais muito mais fracos em sua capacidade de prever a "certeza" em determinadas circunstâncias.

Agora, a natureza dos riscos incorridos e os sinais preocupantes que emanam da esfera científica levam a sociedade a mobilizar suas forças para enfrentar a incerteza incomum. Parece que estamos testemunhando o surgimento de um fluxo de incerteza político-social, voltado principalmente para o mundo científico, sua produção e hesitações.

Seria interessante saber quais são os atores mais indicados para definir a duração do status de pendência dessa nova incerteza político-social. Na maioria das vezes, serão os cientistas que podem dissipar a incerteza, depois de proporcionarem um complemento de especialização para a sua produção. Ainda assim, é possível que o mundo político recorra ao princípio da precaução para ganhar tempo - para reeleição, por exemplo 
- ou para retardar o processo e permitir que a sociedade redefina novos padrões de aceitação da incerteza.

\section{Discussão: o princípio da precaução como uma ferramenta estratégica para redesenhar a (sub)política}

A sociedade de risco sob o paradigma da precaução é caracterizada pela indefinição das fronteiras entre os campos político e não-político. De fato, o mundo político hoje é responsável pelos efeitos latentes, produzidos pela atividade científica do mundo não-político. O mundo nãopolítico, por outro lado, cria hoje as inovações que serão responsáveis pelas grandes transformações sociais e políticas de amanhã. Esta é a razão pela qual Ulrich Beck afirma que a atividade técnico-econômica tornouse subpolítica (Beck, 2001:404). Sabemos que os atores subpolíticos (não só a ciência e a economia, mas também a mídia, o mundo jurídico, a esfera privada, as ONGs...) tomam decisões eminentemente "políticas", que afetam a comunidade como um todo, mas estão fora do controle democrático (Brunet, 2007). Dessa forma, os atores continuam vivendo em uma estrutura mais apropriada à sociedade industrial. Nesta sociedade, as instituições políticas tradicionais estavam (ficcionalmente) no centro único das decisões políticas formais, contanto que houvesse coesão entre atores políticos e subpolíticos. É possível ter uma idéia dessa coesão, examinando o surgimento dos estados de bem-estar social na Europa, quando as elites políticas, sociais e econômicas criaram políticas sociais e econômicas para apoiar o desenvolvimento de inovações tecnológicas que foram decididas na esfera subpolítica. Agora, é preciso abandonar a postura "como se" da sociedade industrial: os cientistas agem como se fossem os donos da verdade, e os políticos como se fossem os donos do poder de decisão. Os atores políticos e subpolíticos devem avaliar 
e aceitar o que são e o que não são e aprender a viver com fronteiras indeterminadas, deixando para trás a divisão de tarefas, já obsoleta, que é característica da sociedade industrial (Beck, 2001:487). Na verdade, ela se faz necessária quando os atores subpolíticos - aqueles da evolução técnico-econômica, por exemplo - tomam decisões que poderiam transformar a sociedade de forma irreversível. De fato, quando confrontado com os efeitos colaterais do desenvolvimento tecnológico, o mundo político deve reagir a posteriori, para lidar com conseqüências que não causou e não impediu, mas pelas quais é responsabilizado pela opinião pública, quando o poder de decisão, na verdade, pertence às entidades subpolíticas: "células revolucionárias escondidas sob o manto da normalidade" (Beck, 2001:472). Nestas circunstâncias, a sociedade, diante da nova incerteza descrita acima, exige, de forma ativa e legítima, uma maior democratização das decisões de caráter técnico-econômico.

O princípio da precaução, como princípio de ação política - e não de abstenção - proporciona aos decisores públicos a possibilidade de sair do jugo da sociedade industrial, a fim de esclarecer as decisões políticas tomadas fora do Parlamento. Eles podem recuperar parte do "poder de decisão política" em determinadas áreas de competência, ou, no mínimo, inibir o poder que outros exercem com impunidade, de forma antidemocrática. Muito mais do que uma confissão da necessidade urgente de impor limites à atividade subpolítica, o princípio da precaução torna possível imaginar uma redução no espaço ocupado por determinadas entidades (entidades econômicas, por exemplo), enquanto outras continuam a se beneficiar da mesma liberdade de circulação. Podemos falar de uma ruptura subpolítica, para diferenciar os atores subpolíticos que serão afetados pela aplicação do princípio da precaução daqueles que continuarão a desempenhar um papel na gestão, geralmente envolvidos com a política. 
Um exemplo característico do uso do princípio da precaução como uma ferramenta de ruptura subpolítica é o caso dos organismos geneticamente modificados (OGMs). Foi a segurança dos OGMs que deu origem à controvérsia e sua disseminação no meio ambiente e comercialização só pôde ser operada depois que os riscos foram avaliados. Mas, mesmo antes de terem sido aprovados, o legislador optou, em conformidade com o princípio da precaução, por obrigar pesquisadores e produtores a identificá-los com antecedência, durante o cultivo dos produtos, para diminuir as incertezas. Mais conhecimento, no entanto, não garante menos incertezas. Este exemplo prova, se for necessário, que o princípio da precaução, em si, não questiona uma etapa científica. Sua lógica consiste em prevenir melhor os danos e pensar melhor as decisões; sendo assim, o princípio da precaução reforça a etapa científica (Noiville, 2003:56-57). Em paralelo, o legislador pode querer reforçar os mecanismos de monitoramento e rastreabilidade dos produtos, a fim de acompanhar os efeitos em larga escala. A União Européia, ao recorrer ao princípio da precaução, vetou o cultivo e a comercialização de OGMs, mas, em contrapartida, pediu uma avaliação complementar. Contrariando os interesses das entidades econômicas da esfera subpolítica, cuja ação foi barrada pelo poder político, os cientistas foram incentivados a aumentar a produção de conhecimento, a fim de saber se era possível dissipar a incerteza. Contudo, a aplicação do princípio da precaução pode ser ainda mais restritiva e barrar a continuidade de qualquer pesquisa científica, como no caso da bioética, ou, mais precisamente, no da clonagem reprodutiva humana. Este tipo de aplicação pode, então, bloquear um processo de reflexão, marketing, ação ou pesquisa, ainda que a medida seja adequada, o risco plausível e os danos potenciais classificados como pouco graves.

A avaliação do risco não pode levar a um resultado inquestionável, ou a uma conclusão monolítica. Deve manter incertezas ou enfatizar opi- 
niões divergentes, para além da corrente científica dominante. No final, o poder político avalia a aceitabilidade do risco, levando em consideração os requisitos médicos, políticos, sociais ou econômicos e decide se é adequado ou não aplicar o princípio da precaução. É necessário, então, um prazo razoável, em conformidade com as circunstâncias específicas de cada caso concreto (Noiville, 2003:153-155).

A cada problema que surge, a prática política que representa o uso desse princípio encantatório sempre limita (pelo menos temporariamente) a margem decisória das entidades subpolíticas. No entanto, permite que outras entidades se beneficiem da mesma liberdade de ação, ao ponto de instigá-las a agirem. Conseqüentemente, seria interessante examinar a linha de ruptura em uma base caso a caso, considerando que esta é constantemente redefinida conforme o contexto do problema, a natureza dos riscos incorridos, os dados disponíveis e os padrões sociais de aceitação de incerteza.

Neste novo contexto, os riscos modernos não podem simplesmente ser reduzidos a novas ameaças. Eles têm de ser entendidos como uma janela de oportunidade a ser expandida, tanto para o mundo político, quanto para o subpolítico. Neste trabalho, demonstramos como a expansão de interpretações científicas acerca de novas ameaças gerou um fluxo de novas fontes de incerteza social. Nestas circunstâncias, os atores políticos tradicionais são levados a gerir problemas técnicos e científicos que, na ausência de regulação política, poderiam causar grandes catástrofes, pelas quais eles seriam responsabilizados pelos cidadãos cada vez mais mobilizados.

Logo, a compreensão dos riscos modernos implica recorrer a novas ferramentas estratégicas, como o princípio da precaução, que permite ao mundo político tomar posse do "poder de decisão política" em campos que, na sociedade industrial, ele não interferia. Ao causar um segundo desencantamento do mundo, os riscos modernos tornaram possível para a sociedade desembaraçar-se de sua passividade e reivindicar um maior in- 
tervencionismo político, adaptado às novas realidades. Através do princípio da precaução, os atores políticos, independente de sua vontade, passam a ocupar domínios que, a priori, não faziam parte de suas competências.

Paradoxalmente, o conceito de risco moderno e os movimentos que provoca no mundo científico, também proporcionam à esfera subpolítica uma oportunidade de expansão. Em uma sociedade industrial onde o paradigma da prevenção consagrou o mito cientificista, os cientistas desfrutaram de imunidade contra críticas externas. Mas a ciência, hoje, está mais humilde, a favor de uma maior abertura e mediação com as esferas pública e política na gestão dos desenvolvimentos técnico-científicos. Por outro lado, algumas questões relacionadas aos riscos modernos oferecem aos cientistas a possibilidade de se livrarem do peso de ter que dizer a Verdade. Em outras palavras, o preço a pagar para manter intacta a legitimidade parece muito alto, sob qualquer circunstância. Obviamente, eles mantêm o monopólio da racionalidade para considerar outros riscos, além dos incômodos riscos modernos, mas, com relação a estes, os cientistas não estão automaticamente encarregados de guiar a ação político-social.

Enquanto as "limitações objetivas" (Beck, 2001:387) eram invocadas para explicar os efeitos da industrialização, hoje é impossível invocar estes mesmos limites para legitimar as condições do progresso científico e seus riscos modernos. Conseqüentemente, os atores subpolíticos, na maioria das vezes, optam por expandir outros mercados, apresentam causas obscuras e transformam erros e problemas em expansão de mercado. Em outras palavras, o mundo subpolítico começa a tirar proveito dos problemas que ele mesmo criou, sem levar em consideração o fato de que ele mesmo é a fonte desses problemas. Nestas circunstâncias, quem perde são os cidadãos. Porque mesmo que o risco seja, até certo ponto, uma excelente oportunidade para mobilizar a esfera pública, as principais 
decisões provavelmente vão ocorrer em outro lugar, em um jogo arriscado, onde ganham alguns atores, e o resto do planeta só tem a perder.

\section{Conclusões: o reencantamento do mundo?}

Seguindo o exemplo de Caronte que, na mitologia grega, leva em seu barco as sombras errantes dos mortos para o reino da morte, os riscos modernos desempenham o papel de "atravessadores", ao criar um arranjo teórico que torna possível compreender a passagem de uma "tecnonatureza" para uma "tecnonatureza politizada", ou do desencantamento do mundo para o que chamamos de "segundo desencantamento do mundo".

Sugerimos uma reflexão sobre a natureza deste segundo desencantamento, que poderia muito bem ser qualificado como reencantamento. É legítimo levantar a questão de termos realmente deixado de evoluir em um mundo encantado, quando o desenvolvimento do mito da superioridade da racionalidade científica colocou a ciência em um pedestal na estrutura de uma ideologia positivista e se distanciou das explicações prévias, heterônimas, do mundo. O desencantamento, segundo Weber, nada mais é do que um deslocamento da sacralização para os cientistas, desencantadores encantados.

Hoje em dia, parece que a certeza não é uma prerrogativa dos cientistas e novos modos de conhecimento estão sendo usados para preencher as lacunas no raciocínio científico. Em outras palavras, o conhecimento mítico e sagrado reaparece na sociedade, de uma forma inesperada. O mesmo vale para os riscos modernos, ainda que sejam parte de uma narrativa específica. Eles são um novo mito para justificar o esforço feito no sentido de evitar o pior.

A fim de ajudar os decisores a lidar com questões sociotécnicas complexas e com uma incerteza científica constrangedora, novas e inovado- 
ras ferramentas conceituais - como o princípio da precaução - têm sido amplamente utilizadas, principalmente nas últimas duas décadas. Mas o princípio da precaução não é uma panacéia. Em um mundo cada vez mais globalizado e interligado, os efeitos de sua aplicação são temporários e locais. Se voltarmos ao exemplo dos OGMs, está claro que os decisores europeus não podiam barrar as ações das entidades econômicas por muito tempo, nem poderiam esperar por uma completa redução das incertezas relacionadas. Eles, pelo menos, poderiam ter levado seus parceiros econômicos e políticos a multiplicar os procedimentos de avaliação de risco através de mecanismos institucionalizados. Mas, em um setor como o da agricultura, onde existe a pressão de um mercado cada vez maior de transgênicos (com o apoio dos países líderes neste domínio: Estados Unidos, Brasil e Argentina), não é possível resistir por muito tempo. De fato, estão sempre surgindo novas tensões na interação das diversas estratégias de governo, decididas em níveis diferentes, por atores variados, em diferentes estruturas. É por isso que as incertezas ambientais e de saúde, relacionadas ao cultivo de transgênicos, ainda não foram totalmente dissipadas. Hoje, com uma estrutura de regulação melhorada, as controvérsias sociais foram consideravelmente reduzidas.

Em outras palavras, não vamos nos deixar seduzir pelo canto das Hespérides. Diante dos interesses econômicos de atores globais - como as multinacionais - que exercem atividades de lobby em todo o mundo, no mais alto nível decisório, a aplicação do princípio da precaução tem um impacto limitado em termos de tempo e/ou escopo. Ainda que não se possa negligenciar esse impacto, resta saber qual será o futuro do princípio da precaução, uma vez que ele não parece ser capaz de assegurar a gestão da incerteza. A resposta simples é que ele necessariamente acompanha os acordos entre órgãos institucionalizados, que podem criar um espaço para a ação reflexiva antecipatória e de apoio à decisão. Para 
colocar de outra forma, o uso político da precaução, como um princípio de ação, só faz sentido se houver interação entre as partes interessadas e se o novo conhecimento antecipatório for produzido não só pelos cientistas, mas com eles. A Avaliação Tecnológica, especialmente a Avaliação Tecnológica participativa, é apenas um exemplo de resposta institucional prática para preparar os atores para viver e tomar decisões em um mundo de mudanças e incertezas (Delvenne, 2011).

Isso serve de incentivo para os métodos participativos (incluindo o envolvimento do público em geral). Mas a participação do público é apenas metade da história e não deve ser definida como contrária à análise especializada, o que resultaria em uma dicotomia desnecessária. A análise especializada e a participação têm muito em comum: as duas estão sujeitas às condições de estrutura (Blok, 2007; Bruun Jensen, 2005), são permeadas por relações de poder (Mouffe, 1993 e 2000), vulneráveis a comportamentos estratégicos, visam à redução da diversidade, ou buscam, na maioria das vezes, o consenso. A questão real é sobre a "abertura" e o "fechamento", como definiu Andrew Stirling em sua análise dos processos de avaliação e dos discursos de uma política mais ampla de ciência e tecnologia (Stirling, 2008). Ele menciona um contraste com o enfoque tradicional nas recomendações prescritivas unitárias (geralmente baseadas em especialização) e descreve como a avaliação aberta apresenta questões alternativas, enfatiza questões negligenciadas, inclui perspectivas marginalizadas, triangula conhecimentos contraditórios, testa sensibilidades a métodos diferentes, considera incertezas ignoradas, examina diferentes possibilidades, e aponta novas opções (Stirling, 2008:279-280). Em algum momento, porém, também sob uma abordagem de precaução, o fecha- 
mento se faz necessário, em plena realização da redução de complexidade que está envolvida na criação do fechamento (Delvenne e Rip, 2010). A verdadeira questão para o "processo de precaução" - a aplicação do princípio e os debates realizados em arenas institucionais ad hoc - é tentar obter um fechamento reflexivo e passível de revisão.

The precautionary principle as a strategic tool for redesigning (sub)politics. Understanding and perpectives from frenchspeaking political science

\section{Abstract}

The precautionary principle falls under a decisional context in evolution, marked by a multidimensional uncertainty as for environmental, economic, social, political or ethical consequences of the technological innovations. In Frenchspeaking political science, it is understood as a strategic tool, a political response to the emergence of a new flow of societal uncertainty, mainly directed towards the hesitations of the scientific world. We argue that the precautionary principle redefines the way to manage scientific uncertainty in a society characterized by the blurring of the borders between political and subpolitical actors. Around its application, a line of fracture is drawn, which reduces the decisional breathing space of certain subpolitical entities and/or encourages others to act more.

Key words: Precautionary principle. Uncertainty.

\section{Referências}

AMIGUETO, O; JULIER, C. L'intervention systémique dans le travail social, Genève: Les Editions I.E.S, 1996.

BECK, U. La société du risque. Paris: Aubier, 2001.

BECK, U.; GIDDENS, A.; LASH, S. Reflexive Modernization. Cambridge: Polity Press., 1994. 
BLOK, A. Experts on Public Trial: On Democratizing Expertise through a Danish Consensus Conference. Public Understanding of Science, 16, 2007.

BRUNET, S. Société du risque: quelles réponses politiques?. Paris: L'Harmattan, 2007.

BRUUN, Jensen C. Citizen Projects and Consensus-Building at the Danish Board of Technology: On Experiments in Democracy. Acta Sociologica, 48-3, 2005.

BLOOR, D. Knowledge and Social Imagery. Londres: Routledge and Kegan Paul, 1976.

CHALMERS, A. Qu'est-ce que la science?. Paris: Éditions La Découverte, 1987.

COMTE, A. Cours de philosophie positive. Paris: Hermann, 1975.

COUSY, H. A propos de la notion de précaution. Risques, $\mathrm{n}^{\circ}$ 21, jan-mar, 1995.

CROZIER, M. Le phénomène bureaucratique. Paris: Seuil, Coll. Points, 1963.

DELVENNE P. Science, technologie et innovation sur le chemin de la réflexivité. Mise en perspective des offices parlementaires de Technology Assessment, Louvain-La-Neuve : Academia Bruylant, 2011. (no prelo).

DELVENNE, P.; RIP, A. Reflexive Modernization in Action: Pathways of Science and Technology Institutions. Social Science Information, 2010.

DUBUISSON, B. Regards croisés sur le principe de precaution. In: HUPET, P. (dir.). Risque et systèmes complexes: les enjeux de la communication. Bruxelles: Peter Lang Edition, 2001.

ERALY, A. Réflexivité, pouvoir, idéologie et rapport à soi. In: AUDET, M.; BOU$\mathrm{CHIKHI}, \mathrm{H}$. Structuration du social et modernité avancée. Sainte-Foy: Les Presses de l'Université Laval, 1993.

EWALD, F. Philosophie de la precaution. L'année sociologique, n 46, 1996a.

EWALD, F. Histoire de I'Etat providence. Col. Biblio-essais. Paris: Grasset, , 1996b.

FEYERABEND, P. Science in a Free Society. Londres: New Left Books, 1978.

FEYERABEND, P. Contre la méthode. Esquisse d'une théorie anarchiste de la connaissance. Paris: Seuil, 1979.

FOUREZ, G. La construction des sciences. Bruxelles: De Boeck, 1986.

GIDDENS, A. Une théorie critique de la modernité avancée. In: AUDET, M.; BOUCHIKHI, H. Structuration du social et modernité avancée, Sainte-Foy: Les Presses de l'Université Laval, 1993. 
GIDDENS, A. The Consequences of Modernity. Oxford: Polity Press, 1997.

GILLIES, D. Philosophy of Science in the Twentieth Century. Oxford: Blackwell Publishers, 1993.

HABERMAS, J. La technique et la science comme idéologie. Paris: Denoël-Gonthier (Médiations), 1978.

HEIDEGGER, M. La question de la technique. In: Essais et Conférences, Paris: Gallimard, 1980.

HEY, E. The precautionary approach, implications of the revisions of the Oslo and Paris Conventions. Marine Policy, jul 1991.

HOTTOIS, G. Le paradigme bioéthique. Une éthique de la technoscience. Col. Sciences éthiques sociétés. Bruxelles: De Boeck Université, 1990.

JONAS, H. Le principe responsabilité: une éthique pour la civilisation technologique. Paris: Les Editions du Cerf., 1990.

JOSS, S.; BELLUCCI, S. Participatory Technology Assessment. European Perspectives. London: Centre for the Study of Democracy, 2002.

KANT, E. Critique de la raison pure. Paris: Aubier, 1997.

KOURILSKY, P.; VINEY, G. Le principe de précaution - Rapport au Premier ministre, Paris: Editions Odile Jacob, La Documentation française, 2000.

KUHN, T. La structure des révolutions scientifiques. Paris: Flammarion, 1983.

LAKATOS, I.; MUSGRAVE, A. Criticism and the Growth of Knowledge, Cambridge: Cambridge University Press, 1974.

LATOUR, B. La vie de laboratoire. Paris: La Découverte, 1988.

LATOUR, B. La science en action. Paris: La Découverte, 1989.

LATOUR, B. Nous n'avons jamais été modernes. Essai d'anthropologie symétrique, Paris: La Découverte, 1994.

$\mathrm{MOL}, \mathrm{A}$. The refinement of production: Ecological modernization theory and the chemical industry. Utrecht: Van Arkel, 1995.

MOL, A.; SPAARGAREN, G. Ecological modernization theory in debate: A review. In: MOL, A.; SONNENFELD, D. Ecological modernization around the world: Perspectives and critical debates. London: Frank Cass, 2000.

MOUFFE, C. The Return of the Political. London and New York: Verso, 1993.

MOUFFE, C. The Democratic Paradox. London and New York: Verso, 2000. 
NOIVILLE, C. Du bon gouvernement des risqué. Paris: Presses Universitaires de France, 2003.

POPPER, K. Conjectures and Refutations. The Growth of Scientific Knowledge. London: Routledge \& Kegan Paul, 1963.

RIP, A.; SCHOT, J. The Past and Future of Constructive Technology Assessment. Technological Forecasting and Social Change, vol. 54-2, 1997.

ROQUEPLO, P. Penser la technique. Paris: Seuil, 1983.

STEBBING, A. Environmental capacity and the precautionary principle. Marine Pollution Bulletin, vol. 24, $\mathrm{n}^{\circ}$ 6, 1992.

STIRLING, A. Opening up' and Closing down. Power, Participation and Pluralism in the Social Appraisal of Technology. Science, Technology \& Human Values, 33, 2008.

WEBER, M. Economie et société. Paris: Plon, 1971.

YORK, R.; ROSA, E. Key Challenges to Ecological Modernization Theory: Institutional Efficacy, Case Study Evidence, Units of Analysis, and the Pace of EcoEfficiency. Organization Environment, vol. 16-273, 2003.

Recebido: $15 / 09 / 2010$

Aceite final: 07/10/2010 